\title{
ARTE GRÁFICA DE PROTESTO: REFLEXÕES ACERCA DOS CARTAZES POLÍTICOS DAS JORNADAS DE JUNHO
}

Rubens Rangel Silva

Universidade Federal de Minas Gerais (UFMG)

rubensrangelbhz@gmail.com

Maria do Carmo de Freitas Veneroso

Universidade Federal de Minas Gerais (UFMG)

cacau_freitas@yahoo.com.br

Resumo: A humanidade tem uma trajetória contínua de guerras e conflitos e as artes gráficas têm papel importante nessa história. Assim como a obra Guernica (1937), de Pablo Picasso, o cartaz pode configurar-se como instrumento de impor supremacia ou salvaguardar interesses culturais, materiais, ideológicos e políticos. Essa importância pode ser observada nas guerras mundiais e civis, nas ditaduras militares e nas insurreições populares ocorridas em diversos países e diferentes tempos. Em junho de 2013 o cartaz político teve grande importância e participação nas manifestações que tomaram as ruas das cidades brasileiras, também conhecidas como Jornadas de Junho. Nesses atos percebeu-se significativa presença da mídia cartaz como ferramenta de expressão e de propagação de ideias. Isso porque o cartaz dialoga rapidamente com as pessoas e o ambiente urbano, acompanhando o desenvolvimento das relações sociais, culturais, econômicas, políticas e tecnológicas.

Palavras-chave: arte gráfica de protesto, Jornadas de Junho, cartaz político.

Abstract: Humanity has a continuous trajectory of wars and conflicts and graphic arts play an important role in this story. As Guernica (1937), Pablo Picasso, the poster can be configured as a tool to impose supremacy or safeguard ionterests cultural, material, ideológical and political. This importance can be seen in the world and civil wars, military dictatorships and the political popular insurrections occurred in different countries and different times. In June 2013 the political poster was of great importance and participation in the manifestations took to the streets of Brazilian cities, also known as June Jorney. These acts perceive a significant presence poster media as tool of expression and propagation of ideas. This is because the poster quickly converses with people and the urban environment, following the development of social, cultural, economic, political and technological.

Keyboard: graphic art of protest, Journey June, political poster. 


\section{INTRODUÇÃO}

Ao direcionar nossa atenção para as diversas vozes das manifestações brasileiras de junho de 2013, também conhecidas como Jornadas de Junho, os temas da fragilidade social vêm de imediato à tona: mobilidade urbana, saúde, educação, segurança pública, políticas inclusivas etc. Isso pode ser observado nas reivindicações e nas palavras de ordem dos atos daquele ano, entretanto, não nos limitaremos à objetividade dessas demandas. Interessa-nos mais escarafunchar em um lugar mais subliminar e subjetivo, onde a expressão é despudorada e espontânea, onde a emoção e o humor eclodem, a raiva e o sarcasmo se manifestam, onde o ato se passa como linguagem, como documento e manifesto histórico, político e visual, mas também, onde os valores partilhados derivados da vida individual e coletiva se impõem: o cartaz político. Nele, a insatisfação, a revolta, a paixão, a pulsão, os afetos e os desafetos se impõem como evidências atordoantes, fazendo das paredes e das ruas das cidades a chave para a articulação de novos pactos entre sujeitos (de)semelhantes e diferentes desejos (PECHMAN, 2014).

Esta pesquisa propõe uma análise crítica das funções estética, criadora, e de ambiência do cartaz político das Jornadas de Junho a partir de um percurso pela antropologia da imagem e pelas ciências sociais. Propõe ainda uma análise que extrapole o caráter exclusivamente comunicacional do cartaz e sugere uma investigação no campo da imagem a partir de alguns conceitos que têm origem na modernidade, tais como as relações entre: arte e cotidiano; arte e política; arte e publicidade; arte e imagens múltiplas; arte e tecnologia, e ainda; entre a arte e a rua. Para tal análise convocaremos alguns conceitos como os de dispositivo e documento, elaborados por Agamben (2009) e Chagas (2013); apresentaremos algumas reflexões e distinções entre publicidade e propaganda, termos discutidos no âmbito da comunicação e das ciências sociais por Hollis (2000), Moles (1974), Sontag (2010), dentre outros; examinaremos as diferenças entre ler e ver a partir dos conceitos de linha e superfície elaborados por Flusser (2007); mostraremos as definições e as diferenciações dos conceitos de multidão, povo e massa, discutidas por Hardit e Negri (2005); além de uma análise direta dos cartazes políticos das Jornadas de Junho.

\section{A CULTURA DO CARTAZ}

Presente no ambiente urbano em conflito o cartaz político atua como uma espécie de dispositivo e tem a capacidade de "capturar, orientar, determinar, interceptar, modelar e assegurar os gestos, as condutas, as opiniões e os discursos dos seres viventes." (AGAMBEN, 2009, p. 40). O conceito de dispositivo, elaborado por Georges Agamben, se aplica perfeitamente ao cartaz, em especial o político, que é uma das aberturas próximas de uma arte não alienada, inserida na vida cotidiana, próxima e espontânea. Por isso, o cartaz político pode refletir o pensamento de uma determinada época, fazendo dele uma espécie de documento. Ele é um importante elemento de informação de movimentos de caráter político, social, econômico e cultural. Além de operar como dispositivo, o cartaz político também pode configurar-se como documento e é constituído como tal 
feito, qual seu autor, de que tema trata, qual sua função, em que contexto sociocultural foi produzido e utilizado, que relação manteve com determinados atores e conjunturas históricas. (CHAGAS, 2013).

O cartaz é um fenômeno da vida urbana moderna e sua linguagem gráfica acompanhou as mudanças e os aperfeiçoamentos dos movimentos artísticos e dos meios de comunicação e reprodução, sendo um reflexo da cultura e do desenvolvimento tecnológico da sociedade. Ele é testemunha da vivência urbana nas cidades modernas, pós-modernas e contemporâneas.

Na definição apresentada por Richard Hollis "o cartaz pertence à categoria da apresentação e da promoção, na qual imagem e palavra precisam ser econômicas e estarem vinculadas a um significado único e fácil de ser lembrado." (HOLLIS, 2000, p. 5). Abraham Moles define o cartaz como uma "imagem, em geral colorida, contendo normalmente um único tema e acompanhado de um texto condutor. É feito para ser colocado e exposto à visão do transeunte." (MOLES, 1974, p. 44).

O conceito de cartaz apresentado por Harold F. Hutchinson, em 1968, possui sentido próximo daqueles apontados pelos autores anteriores, corroborando com a compreensão de que o cartaz é a mídia que se mostra ao público como

\begin{abstract}
um anúncio grande, normalmente com um elemento pictórico, normalmente impresso em papel e normalmente exposto em uma parede ou quadro para o público em geral. Seu objetivo é chamar a atenção para qualquer coisa que o anunciante esteja tentando promover e gravar uma mensagem no transeunte. O elemento visual ou pictórico proporciona a atração inicial - e ele dever ser suficientemente impressionante para prender o olhar do transeunte e superar a atração concorrente dos outros cartazes, de modo que precisa de uma mensagem verbal suplementar que reforce e amplifique o tema pictórico. 0 tamanho grande da maioria dos cartazes permite que a mensagem verbal seja lida claramente a distância. (HUTCHINSON, 1968 apud SONTAG, 2010, p. 211).
\end{abstract}

A partir dessas e de outras definições podemos perceber, dentre outras coisas, que o cartaz é predominantemente composto pela interação palavra/imagem. O cartaz é linha e superfície, ou seja, pode ser lido de forma linear e não linear. O termo "linha" é empregado por Vilém Flusser (2007) na acepção dos textos escritos, em contraponto ao temo "superfície" que define o modo de leitura das imagens (FLUSSER, 2007, p. 102). O cartaz é livre para agregar palavra e imagem (linha e superfície), mesclando recursos linguísticos e pictóricos, bem como para escolher apenas um ou outro recurso. O que também caracteriza o cartaz é o fato de nunca estar só, "de jamais proclamar sua unicidade, mas ser por essência múltiplo, tributário do mecanismo de cópia, ligado a uma interação dos estímulos para dar lugar a uma cultura global." (MOLES, 1974, p. 231).

O processo de emissão de uma mensagem pelo cartaz é caracterizado por um aspecto dinâmico de repetição. Após certo tempo é possível que o conteúdo da mensagem "descole-se" da necessidade de um amparo material: a mensagem do cartaz "gruda" na mente do indivíduo. "O cartaz se decalca pouco a pouco no cérebro dos membros da sociedade para aí se constituir num elemento da cultura." (MOLES, 1974, p. 27). Ele constrói reflexos condicionados, slogans e estereótipos que se imprimem na cultura individual e coletiva. 
Além das funções estética, propaganda e publicidade, o cartaz também exerce outras funções na sociedade. Abraham Moles (1974) apresenta seis delas desempenhadas pelo cartaz numa sociedade de consumo: 1) a primeira está ligada mais diretamente à informação, a seu papel de anunciador de algo e, por isso, à linguística, a uma semântica geral das coisas; 2) a segunda função, propaganda ou publicidade, está relacionada à difusão de ideologias e ao consumo de bens e serviços; 3) a terceira é a da educação, vinculada aos problemas do repertório de conhecimentos, da psicologia social e da cultura; 4) a quarta função, a da ambiência, está ligada à psicologia do ambiente urbano; 5) a quinta, estética, está ligada ao poder de atração do cartaz e às técnicas de fabricação e; 6) a sexta, a função criadora do cartaz, ligada à expressão artística (MOLES, 1974, p. 53-57).

Embora seja difícil definir quando se deu o nascimento do cartaz moderno tal como o conhecemos hoje, um ponto de partida para se compreender sua história, em linhas gerais, são os anos de 1860, quando o pintor e litógrafo Jules Chéret (18361933) começou a produzir cartazes litográficos a cores em sua própria prensa. O cartaz moderno surgiu a partir da união da arte com as então recentes técnicas de reprodução: a litografia e a cromolitografia. Para usar uma expressão de Walter Benjamin, o cartaz é fruto da "época e de suas técnicas de reprodução." A difusão da litografia e da cromolitografia foi uma das grandes responsáveis pelo desenvolvimento das artes gráficas, em especial, a linguagem gráfica do cartaz no final do século XIX.

O cartaz moderno nasceu com o objetivo de apresentar novos produtos e espetáculos, promovendo o consumo de mercadorias e o apetite privado, ou seja, a publicidade capitalista, mostrando o consumismo crescente e os costumes da vida burguesa da época. Com o surgimento de sua função de propaganda ideológica e política o cartaz passou também a mobilizar e dar voz às multidões, insurgindo contra os abusos dos poderes políticos, questionando os governos e problematizando as ações dos Estados-nação, ou seja, além de ser reflexo dos costumes e dos estilos e escolas artísticas tornou-se também documento histórico das relações sociopolíticas.

\section{O CARTAZ POLÍTICO}

Existe uma grande diferença de contexto entre o cartaz político e o cartaz comercial. Este é "fruto da economia capitalista, com sua necessidade de induzir as pessoas a gastar mais em bens não essenciais e espetáculos" (SONTAG, 2010, p. 216). Já o cartaz político tem por objetivo a educação universal e a mobilização das multidões, uma vez que o cartaz de propaganda ideológica - o cartaz político - "decora ideias compartidas e estimula simpatias morais" (Idem, p. 249). Enquanto "a presença do cartaz de publicidade comercial geralmente indica o nível em que uma sociedade se define como estável e em busca de um status quo econômico e político" (Idem, p. 217), a presença do cartaz político mostra o estado de emergência em que se encontra a sociedade ele pode indicar uma crise econômica e política, um período de guerra ou uma luta pela construção de uma nação mais democrática.

É importante, nesse contexto, definir o conceito de "multidão", que se distingue de "povo" e "massa". O povo tem uma concepção unitária. "A população é caracterizada pelas mais amplas diferenças, mas o povo reduz essa diversidade a uma unidade, transformando a população em uma identidade única" (HARDT; NEGRI, 2005, p. 12). Já a multidão é plural, "se compõe de inúmeras diferenças internas que nunca 
poderão reduzir-se a uma unidade, nem a uma identidade única" (Idem, p. 12). Há diferenças de cultura, raça, gênero e sexualidade, ou seja, diferentes formas de viver, ver e estar no mundo. Por sua vez, as massas também se diferem de povo, já que não podem ser reduzidas a uma unidade ou a uma identidade única. "É certo que as massas são compostas de tipos de todas as classes, mas não se pode afirmar que as massas são compostas de sujeitos sociais diferentes" (Idem, p. 13). A essência das massas é a indiferenciação: "todas as diferenças submergem nas massas. Todas as cores da população reduzem-se ao cinza" (Idem, p. 13). Na multidão, pelo contrário, "as diferenças sociais mantêm-se diferentes, a multidão é multicolorida." (idem, p. 13). O desafio do conceito de multidão consiste em que uma multiplicidade social consiga comunicar-se e atuar em comum, conservando suas diferenças internas.

Essas diferenças, evidentemente, provocam contrastes que modificam a rua, que por sua vez modifica a cidade, que modifica o sujeito. Este último é o "resultado da relação e, por assim dizer, do corpo a corpo entre os seres viventes e os dispositivos." ${ }^{1}$ (AGAMBEN, 2009, p. 41). Em junho de 2013, a simples ideia de uma rua convulsionada por sujeitos incontroláveis, cheios de desejos inesperados, assustou os poderes constituídos. As multidões tomaram as ruas e o rotineiro esquivamento do outro deu lugar à comunhão. No ato político-popular

\begin{abstract}
o contato se estreita, a cidade supera sua mudez pelas ruas que falam, berram, gritam numa língua/linguagem antibabélica que todos conseguem entender. $\mathrm{O}$ mito da cidade se atualiza, possibilitando novas narrativas que se manifestam tentando dar sentido ao absolutamente novo: diante de enunciados que evocavam um funcionamento pulsional da cidade, impõe-se uma novíssima narrativa cidadã, vazada no simbólico e que por isso mesmo se estrutura na linguagem. (PECHMAN, 2014).
\end{abstract}

Essa linguagem simbólica manifestou-se nas ruas sintomaticamente em forma de cartazes, elaborados espontaneamente "e por isso mesmo tendo a potência de ecoar a multiplicidade de críticas, abordagens, percepções e linguagens que se impuseram, construindo um discurso de resistência e mesmo de proposição à situação vigente." (PECHMAN, 2014).

\title{
4. O CARTAZ POLÍTICO NAS JORNADAS DE JUNHO
}

A partir da observação e participação em alguns atos das Jornadas de Junho, percebemos alguns aspectos relativos aos cartazes políticos: 1) o considerável volume de cartazes produzidos; 2 ) a variedade de estilos gráficos; 3 ) a relação desses cartazes com a paisagem urbana; 4) a utilização de uma mídia de comunicação em massa para o indivíduo e do indivíduo para as multidões e; 5) o caráter estético, artístico e criador desses cartazes. A partir dessa participação e extensa pesquisa sobre os cartazes das Jornadas de Junho - num universo de mais de 300 cartazes por nós arquivados/colecionados - percebemos os contornos dos protestos, as diferentes demandas e o quebra-cabeça de insatisfações sociais que motivaram a insurreição.

\footnotetext{
${ }^{1}$ Agamben, em seu livro $O$ que é dispositivo? propõe uma divisão em dois grandes grupos ou classes: de um lado, os seres viventes (ou as substâncias) e, de outro, os dispositivos. Da relação entre essas duas classes surge o sujeito. AGAMBEN, Giorgio. O que é contemporâneo? e outros ensaios. Chapecó: Argos, 2009.
} 
Organizamos esses cartazes em quatro grandes grupos analíticos, definidos a partir de suas técnicas de fabricação/reprodução e de seus meios de circulação/veiculação, são eles: 1) Cartaz itinerante; 2) Lambe-lambe; 3) Cartaz profissional e; 4) Cartaz digital. Analisemos, na sequência, esses quatro grupos: ${ }^{2}$

\subsection{Cartaz itinerante}

O cartaz itinerante é um tipo fundamental de símbolo público por evidenciar as opiniões individuais e coletivas, estimular a solidariedade e incitar a revolução e a participação no ato em que os protestos acontecem. O objetivo desse cartaz é despertar a consciência política, o propósito mais elevado das manifestações. Empunhar um cartaz político em um manifesto é estar ativo na opinião política e social. Esses cartazes são produzidos de forma artesanal e em versões únicas, normalmente em cartolina, papel cartão, kraft ou pedaço de papelão. São desenhados à mão com a utilização de canetão, canetinha, tinta guache, colagem etc. Seus formatos são variados e ocupam o mesmo lugar do corpo do manifestante: as ruas das cidades. Encontra-se neles grande uso do recurso textual e uma enxuta utilização de símbolos. Nesses cartazes identifica-se o elemento vernacular, que surge como recurso às necessidades específicas do meio. ${ }^{3}$ Nas Jornadas de Junho os cartazes de rua itinerantes funcionaram como uma extensão do corpo, amplificando a voz do manifestante. Em alguns casos a interpretação desses cartazes estava semanticamente ligada à imagem de seu portador, que assumia um personagem para complementar a mensagem. A metáfora visual, a agressividade, a criatividade e a irreverência foram artifícios dos cartazes de protesto das Jornadas de Junho. O humor e a criatividade desses cartazes ganharam força de protesto e anedota gráfica, satirizando o comportamento humano. Bastante conhecido em ações de manifestação política, o elemento satírico desperta a atenção do espectador para o assunto ao mesmo tempo em que facilita a sua atenção por parte do leitor (NEVES, 2009, p. 122). Aliado a signos culturais, o humor nos cartazes políticos é um recurso bastante eficiente. O cartaz itinerante é simples e a qualidade gráfica demandada para as intervenções não é muito exigente. Torna-se muito fácil participar, produzindo uma versão "original" ao invés de apenas retransmitir uma já existente. Apesar de não estar na vanguarda, em termos estéticos, o cartaz de rua itinerante motivou e inspirou a produção de diversos cartazes de profissionais do design e das artes gráficas. Sua tarefa foi ratificar, reforçar e difundir os valores defendidos pelos manifestantes.

\footnotetext{
2 Uma coleção com cartazes das Jornadas de Junho, organizada pelo autor (edição pessoal), pode ser conferida no link https://issuu.com/rubensrangel/docs/coletivo_jornadas_de_junho.

3 Despido do conhecimento formal, que cerca o "design erudito", o design vernacular encontra-se presente em placas e artefatos de uso popular produzidos por habitantes locais sem formação na área do design. Isso não significa que inexista uma intenção, um propósito ou um problema a ser enfrentado e resolvido (VALESE, 2007, p. 15).
} 

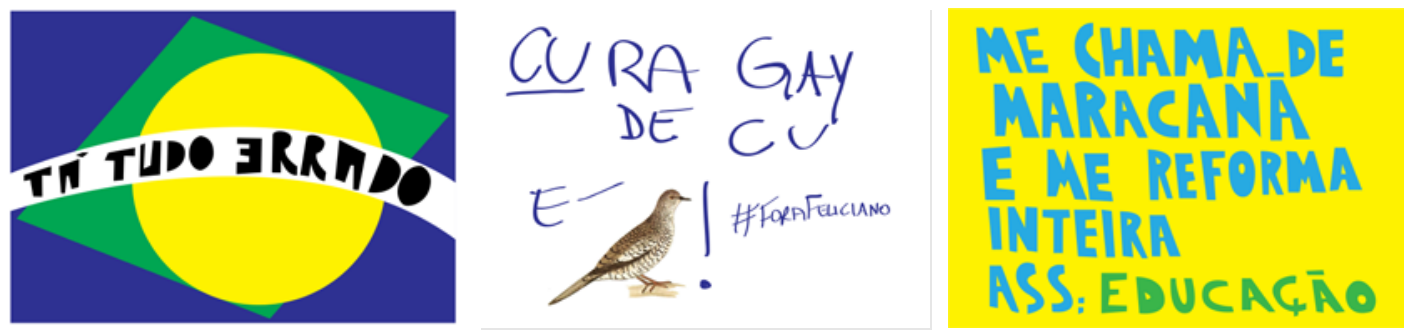

Figura 1 - Cartazes itinerantes

Fonte: SILVA, Rubens Rangel. Coletivo Jornadas de Junho. Belo Horizonte: Insecta (edição do autor), 2015.

\subsection{Lambe-lambe}

O lambe-lambe, também um cartaz de rua, ocupa o mesmo lugar do grafite e é por si só subversivo e por isso tão intrínseco aos manifestos sociais e políticos. Sua fácil reprodução e repetição no meio urbano permitem levar uma mensagem complexa e cheia de nuances a um grande número de locais. Tal repetição faz com que as pessoas se familiarizem com sua mensagem e aumenta as chances de reflexão sobre ela. 0 lambe-lambe pode ter tamanhos variados e é fixado em espaços públicos. Pode ser pintado individualmente ou produzido em série por fotocopiadoras ou silkscreen, preferencialmente em papel fino para aderir melhor à superfície. São fixados com grude ou cola de papel em muros, paredes, postes, pontes, fachadas de prédios, bancos, pontos de ônibus etc. O lambe-lambe faz parte das novas linguagens da arte urbana contemporânea e, normalmente, expressa informações e ideias mais complexas que o cartaz itinerante. Nesse caso, um bom design é importante para mostrar essas ideias. A maioria das pessoas o vê à distância e em movimento, fazendo com que seja elaborado de forma mais planejada. Esses cartazes têm propósitos principalmente artísticos e de ativismo social e político. O lambe-lambe leva a arte e o protesto para as ruas das cidades de forma mais prolongada. Nos protestos das Jornadas de Junho eles fizeram ecoar a voz do manifestante, fazendo com que suas ideias reverberassem pelas ruas mesmo findado o movimento. $O$ lambe-lambe é um índice, ou seja, ele é o indício da presença de um acontecimento. Durante as Jornadas de Junho, alguns sites disponibilizaram lambe-lambes de forma livre para reprodução. ${ }^{4}$ Nesses sites encontra-se galerias de cartazes com as mais diversas técnicas de criação e estilos gráficos, disponibilizados sem restrição autoral quanto ao uso, para download em arquivos de alta resolução a fim de que sejam impressos e distribuídos livremente. A gráfica Meli-Melo, de São Paulo, na época das Jornadas de Junho, iniciou um movimento pelo fecebook convocando os internautas a enviarem seus cartazes políticos para que fossem impressos e distribuídos durante os protestos.

\footnotetext{
${ }^{4}$ Acessar em <http://poro.redezero.org/ver/cartazes> e <http://pt.protopia.at/wiki/Lambe-lambe>.
} 

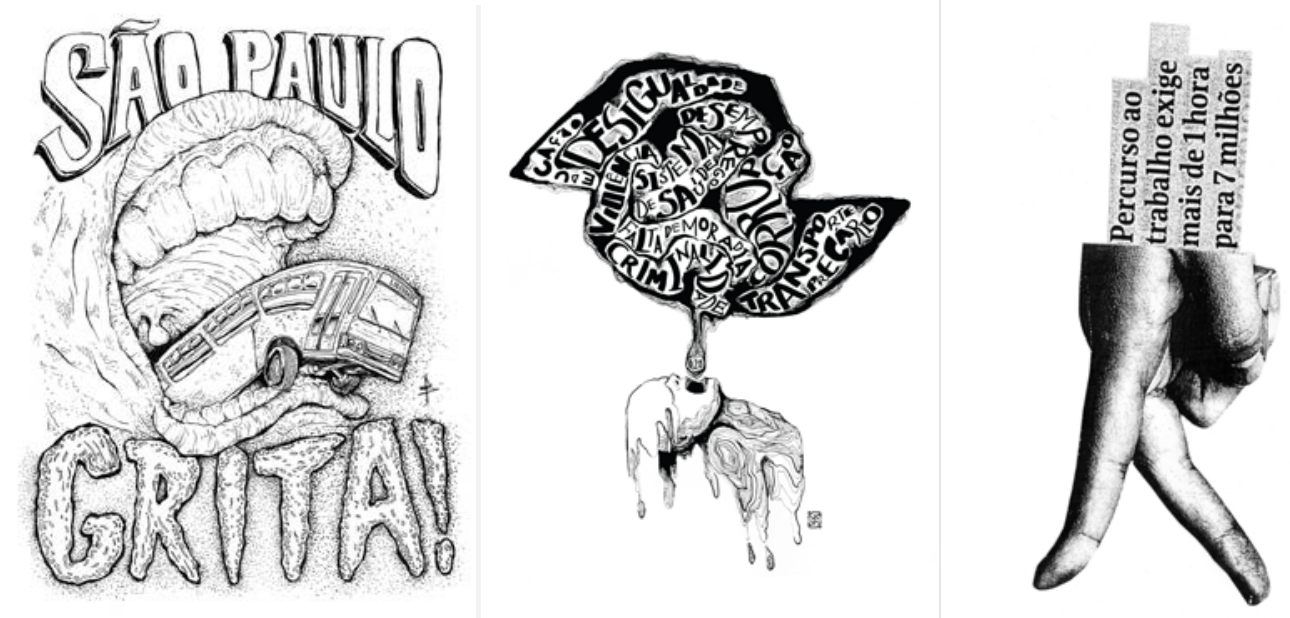

Figura 2 - Lambe-lambes

Fonte: SILVA, Rubens Rangel. Coletivo Jornadas de Junho. Belo Horizonte: Insecta (edição do autor), 2015.

\subsection{Cartaz profissional}

Juntamente com os conflitos surgem grupos da sociedade civil que se mobilizam com o objetivo de apoiar o movimento revolucionário e protestar contra os abusos políticos. Nesses movimentos algumas ações envolvem o uso de material gráfico para a divulgação de ideias. É aí que profissionais e organizações do design propõem cartazes políticos. Além do uso de elementos gráficos recorrentes em conflitos, tais como símbolos nacionais, constata-se uma relevante variedade de estratégias visuais utilizadas nos cartazes profissionais das Jornadas de Junho. No design gráfico pode-se dizer que todo assunto apresenta seus clichês visuais. Nos cartazes das Jornadas de Junho encontramos referências aos símbolos nacionais como a bandeira do Brasil e o Brasão da República, ao punho cerrado, indicando resistência e união, ao povo em protesto, fazendo alusão aos grandes movimentos e à união popular, aos líderes e pensadores políticos, muitas vezes para satirizá-los, às flores e às pombas, indicando solidariedade e paz. A utilização desses símbolos para muitos reduz a obra gráfica, no entanto, fazer um bom uso deles é de extrema importância para o reconhecimento de uma estética nacional e "eles são capazes de remeter de imediato a uma rede de referências simbólicas." (MELO, 2012, p. 249). Apesar de sua visibilidade não ser tão expressiva quanto a dos cartazes de rua e os digitais, os cartazes profissionais ganharam em reprodutibilidade e qualidade gráfica. Nas Jornadas de Junho ocuparam principalmente os espaços internos, levando os protestos também para os espaços privados. Muitos desses cartazes foram disponibilizados gratuitamente e em alta resolução na internet para serem impressos e distribuídos em todo o país. 

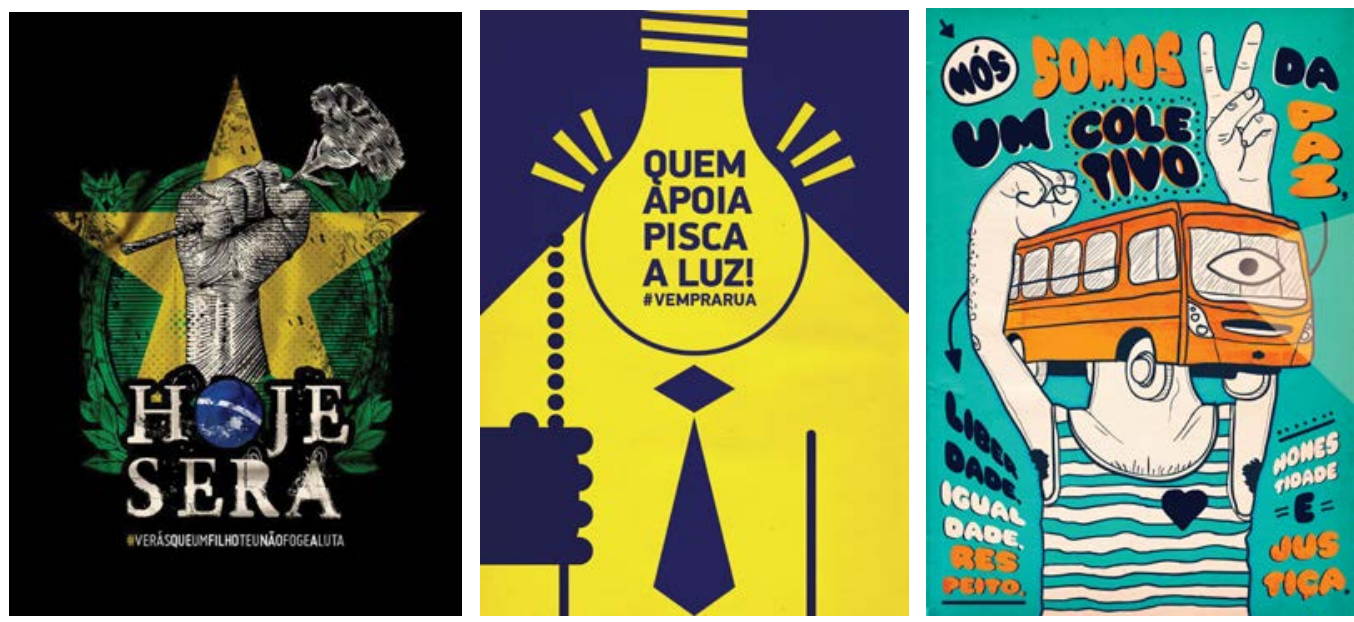

Figura 3 - Cartazes profissionais

Fonte: SILVA, Rubens Rangel. Coletivo Jornadas de Junho. Belo Horizonte: Insecta (edição do autor), 2015.

\subsection{Cartaz digital}

Como resposta aos movimentos iniciados em junho de 2013, pessoas de todo o país começaram a se mobilizar pela internet, trocando informações a respeito dos protestos, compartilhando suas opiniões, apoiando o movimento e se organizando para ganhar força e volume popular, o que culminou nos grandes protestos organizados de junho de 2013. Sobre a potência da internet escreveu Pierre Lèvy:

Em primeiro lugar, que o crescimento do ciberespaço resulta de um movimento internacional de jovens ávidos para experimentar, coletivamente, formas de comunicação diferente daquelas que as mídias clássicas nos propõem. Em segundo lugar, que estamos vivendo a abertura de um novo espaço de comunicação [...] (LÈVY, 1999, p.11).

A internet foi o principal veículo de divulgação das manifestações e, além de intermediar a troca de informações acerca dos protestos, ela foi um importante meio de distribuição de material gráfico. A importância e a repercussão dos manifestos associadas à criatividade dos cartazes digitais fizeram com que alguns deles entrassem em "efeito viral" 5 . Compartilhar uma imagem nas redes sociais é uma forma de auto expressão, que diz algo sobre si mesmo e o que você pensa. Muitas imagens realizadas para os protestos de 2013 circularam na internet, principalmente nas redes sociais. É o caso da coleção \#ChangeBrazil produzida pelo Isabela Rodrigues Sweet Branding Studio, fortemente influenciada pelos cartazes de rua. Essa coleção, com cartazes digitais em formato quadrado para melhor visualização nas redes sociais, foi elaborada com tipografia sem serifa ${ }^{6}$, cores chapadas e texto acompanhado de símbolo. Seu foco está no público jovem conectado à internet. Suas mensagens relacionam-se às novas gerações com irreverência e ironia cáustica. Os temas mais variados relacionados aos

\footnotetext{
${ }^{5}$ Viral é um termo que surgiu junto com o crescimento do número de usuários de blogs e redes sociais na internet. É utilizado para designar os conteúdos que acabam sendo divulgados por muitas pessoas e ganham repercussão na web.

${ }^{6}$ Pequenos traços e prolongamentos que ocorrem no fim das hastes das letras.
} 
protestos foram abordados nesses cartazes. Sua linguagem é tipicamente digital e dialoga com as mais recentes linguagens gráficas.
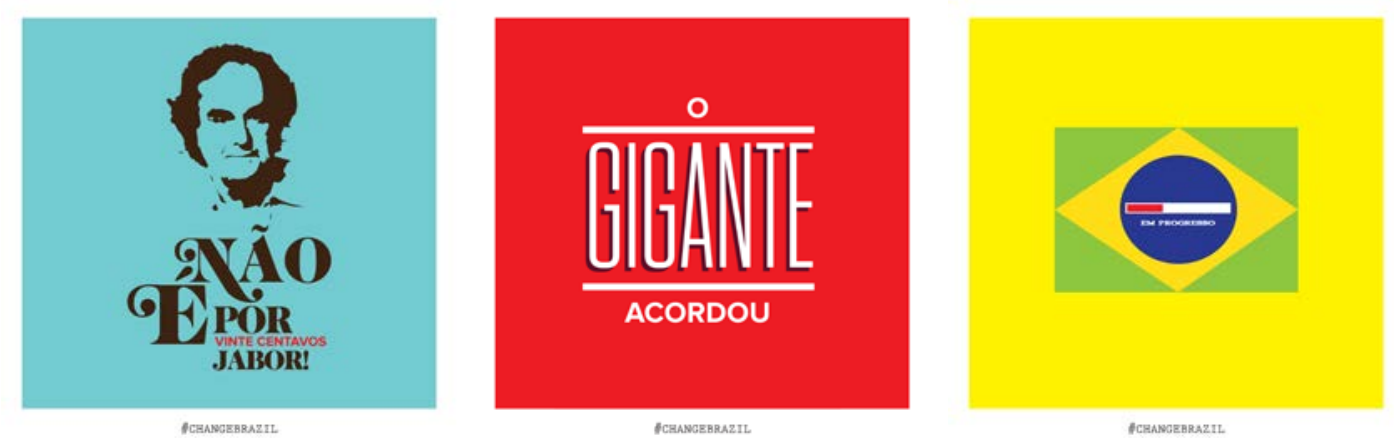

Figura 4 - Cartazes digitais

Fonte: SILVA, Rubens Rangel. Coletivo Jornadas de Junho. Belo Horizonte: Insecta (edição do autor), 2015.

Segmentar as características básicas de cada grupo de cartazes é uma forma de organizar o material para uma análise mais detalhada. A importância em se pensar o cartaz político está na oportunidade em pensar a maneira pela qual compartilhamos os espaços em comum. A hipótese que levanto é que esses cartazes, elaborados ao modo irônico e lúdico, crítico e denunciador, visam a criar ou a recriar, pela diferença, ligações entre os indivíduos, suscitar novos modos de confrontação, participação e relação entre os sujeitos que os levam, por meio da linguagem e do simbólico, a uma redistribuição dos lugares e da partilha.

\section{CONSIDERAÇÕES FINAIS}

As estratégias gráficas e o processo de construção das mensagens visuais nos cartazes das Jornadas de Junho resultaram em uma vasta produção gráfica que demonstra a relevância na escolha do cartaz como comunicador, como representante histórico e tecnológico de seu tempo, como elemento propulsor da mobilização social e como documento histórico de um povo e sua nação. Esta pesquisa procurou evidenciar o valor estético e histórico do cartaz político, observando como ele reflete o período político e a estrutura social de suas nações. Com a análise dos cartazes das Jornadas de Junho tentamos mostrar como essa mídia é um retrato da cultura, da tecnologia e das relações sociais de seus períodos. Nesse processo de construção das mensagens visuais dos cartazes das Jornadas de Junho, a busca por uma comunicação de protesto resultou em uma vasta produção gráfica que demonstra a relevância na escolha do cartaz como comunicador, como representante histórico e tecnológico de seu tempo, como elemento propulsor da mobilização social e como documento histórico de um povo e de sua nação.

O design gráfico é uma atividade capaz de influenciar as atitudes, o comportamento e o conhecimento das pessoas. Partindo dessas habilidades, é interessante pensar e defender sua utilização na busca por ideais maiores na profissão e, consequentemente, na sociedade. É importante estimular a consciência crítica dos designers, enfatizando que seu trabalho vai além da mera questão estética, partindo para a conscientização em relação aos efeitos sociais, culturais e políticos de seus trabalhos. 


\section{REFERÊNCIAS}

AGAMBEN, Giorgio. O que é contemporâneo? e outros ensaios. Chapecó: Argos, 2009.

CHAGAS, Mário. Cultura, Patrimônio e Memória. In: Revista Museu: cultura levada a sério. 2013. Disponível em: <http://www.revistamuseu.com.br/18demaio/ artigos.asp?id=5986>. Acesso em: 18 ago. 2015.

FLUSSER, Vilém. O mundo codificado: por uma filosofia do design e da comunicação. São Paulo: Cosac Naify, 2007.

HARDT, Michael; NEGRI, Antonio. Multidão: guerra e democracia na era do Império. Trad. Clóvis Marques. Rio de Janeiro: Record, 2005.

HOLLIS, Richard. Design gráfico: uma história concisa. Trad. Carlos Daudt. 2a. tiragem. São Paulo: Martins Fontes, 2000.

LÉVY, Pierre. As tecnologias da inteligência: o futuro do pensamento na era da informática. São Paulo: Editora 34, 1993.

MELO, Chico Homem de. Linha do tempo do design gráfico no Brasil. São Paulo: Cosac Naify, 2011.

MOLES, Abraham Moles. O cartaz. São Paulo: Perspectiva, 1974.

NEVES, Flávia de Barros. Design gráfico e mobilização social. 2009. 148 f. Dissertação (Mestrado). Universidade do Estado do Rio de Janeiro, Escola Superior de Desenho Industrial, Rio de Janeiro, 2009.

PECHMAN, Robert Moses. No avesso dos cartazes, uma Cidade Perversa. In: PEIXOTO, Elane Ribeiro; DERNTL, Maria Fernanda; PALAZZO, Pedro Paulo; TREVISAN, Ricardo (Org.). Tempos e escalas da cidade e do urbanismo: Anais do XIII Seminário de História da Cidade e do Urbanismo. Brasília, DF: Universidade Brasília- Faculdade de Arquitetura e Urbanismo, 2014. Disponível em:

<http://www.shcu2014.com.br/content/no-avesso-dos-cartazes-cidadeperversa>. Acesso em: 11 ago. 2015.

SONTAG, Susan. Pôster: anúncio, arte, artefato político e mercadoria. In: BIERUT, Michael; HELFAND, Jessica; HELLER, Steven; POYNOR, Rick; SANTOS, Fernando. Textos clássicos do design gráfico. Trad. Fernando Santos. São Paulo: Martins Fontes, 2010, p. 210-235.

VALESE, Adriana. Design vernacular urbano: a produção de artefatos populares em São Paulo como estratégia de comunicação e inserção social. 2007. 107 f. Dissertação (Mestrado em Comunicação e Semiótica) - Pontifícia Universidade Católica de São Paulo - PUC/SP, São Paulo, 2007. 